\title{
QUALITY MANAGEMENT SYSTEM FOR THE AEROSPACE INDUSTRY
}

\author{
Branislav TOMIĆ ${ }^{1}$, Vesna SPASOJEVIĆ-BRKIĆ ${ }^{2}$, Milivoj KLARIN ${ }^{3}$ \\ ${ }^{1}$ Bombardier Aerospace, Toronto, Canada. \\ ${ }^{2}$ University in Belgrade, Faculty of Mechanical Engineering, 11000 Belgrade, Kraljice Marije 16, Republic of Serbia. \\ Corresponding author. E-mail: vspasojevic@ mas.bg.ac.rs \\ ${ }^{3}$ University of Novi Sad, Technical faculty "Mihajlo Pupin” in Zrenjanin, 23000 Zrenjanin, Đure Đakovića bb, \\ Republic of Serbia.
}

Accepted 1 October, 2011

\begin{abstract}
Initially released in October 1999 by the Society of Automotive Engineers in the United States and Canada, and the European Association of Aerospace Industries in Europe, and shortly thereafter by standards organizations in Japan and Asia, AS9100 has been resulted as a cooperative effort of the International Aerospace Quality Group. As such, it combines and harmonizes aerospace requirements outlined in previously different aerospace standards. AS9100 Revision C was issued in 2009 and it was revised to align with ISO 9001:2008 requirements. This article tries to explain why and where this standard is different than common ISO 9001 standard along with the benefits that result from its implementation.
\end{abstract}

Keywords: aerospace, quality, management, system, standard.

\section{INTRODUCTION}

To assure customer satisfaction, aerospace industry organizations must produce, and continually improve safe, reliable products that meet or exceed customer and regulatory requirements. The globalization of the aerospace industry, and the resulting diversity of regional/national requirements and expectations, has complicated this objective. End-product organizations face the challenge of assuring the quality of, and integration with, product purchased from suppliers throughout the world and at all levels within the supply chain. Aerospace suppliers and processors face the challenge of delivering product to multiple customers having varying quality expectations and requirements. This document (AS9100) standardizes quality management system requirements for the aerospace industry. The establishment of common requirements for use at all levels of the supply-chain by organizations around the world should result in improved quality and safety and decreased costs due to the elimination or reduction of organizationunique requirements and the resultant variation inherent in multiple expectations.

Perhaps no other industry is as obsessively safetyconscious as the Aerospace industry. Constantly under public examination, and with little margin for error, strict quality control standards are now considered standard in every aspect of the industry. In an extremely competitive global landscape, almost all the successful manufacturers, suppliers and service providers today regard quality management as their fundamental driving force. To demonstrate this commitment, however, it is required independent certification. It is irrefutable evidence that quality standards are being met. Such certification can mean winning new contracts, or being excluded. AS9100 standard is the internationally recognized quality system standard specific to the Aerospace industry. Known as AS9100 in North America, EN9100 in Europe and JISQ 9100 in Japan, the standard is strongly supported and adhered to by major aerospace manufacturers including Boeing, Airbus, Bombardier, Pratt \& Whitney, Lockheed Martin, Goodrich, Messier-Dowty, GEAE, Rolls-Royce and others. AS9100 is a widely adopted and standardized quality management system for the aerospace industry. It was released for the first time in October, 1999 (Revision A), by the Society of Automotive Engineers and the European Association of Aerospace Industries and it was a cooperative effort of the International Aerospace Quality Group and as such, it combines, harmonizes and aligns the requirements outlined in ISO 9001. 
Indeed, AS9100 certification has already become the basic requirement demanded by all these companies to their suppliers. Based on ISO 9001 requirements, AS9100 puts a particular focus on quality, safety and technology in all disciplines throughout the industry, and along the entire supply chain. It applies to every domain whether civil or military. AS9100 was established when the aerospace industry realized that it was necessary to supplement the ISO quality management system model to satisfy internal, government and regulatory requirements for the aerospace industry. AS9100 standard comprises the ISO 9001 requirements augmented by additional aerospace industry requirements. It was the result of an international effort by aerospace companies with a common goal of establishing a quality management system for use within the aerospace industry.

\section{AS9100 STANDARD}

AS9100 Standard represents the first international effort to formulate a quality management system standard for the aerospace industry. In its usage, it shows its long-term value. The standard supplements ISO 9001 by addressing the additional expectations of the aerospace industry. AS9100 has already got 3 revisions. The latest one was released in 2009 (Revision C) to align with the standard ISO 9001:2008. The difference between the ISO 9001:2008 text and the AS 9100 (2009) text is in the bold, italic text that represents the aviation, space and defense specific additions.

Among other benefits, AS9100 has been proved as good practice for complicated manufacturing chain and one of the crucial benefits is AS9100's contribution to more consistent verification methods and fewer verification suppliers' audits.

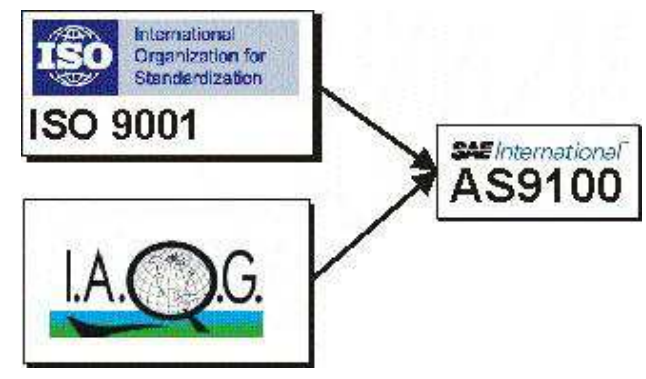

Figure 1: AS9100 - ISO 9001 and additional Aerospace requirements identified by International Aerospace Quality Group (I.A.Q.G.)

According to Dale (2010), AS9100 defines additional areas within an aerospace quality management system that must be addressed when implementing an ISO 9001-based quality system. Typically, these requirements are included within robust aerospace quality systems. The industry experts who wrote the standard and the representatives who approved it all agree that these additions are essential to ensure product, process and service safety and quality.

All quality systems must be designed to meet the specific needs of the users. And although AS9100 identifies areas to address within the aerospace industry, system designers are encouraged to first establish a robust quality system that's both effective and efficient. This system should be a holistic entity with practices spanning multiple functions and processes within the business.

For example, regulatory requirements are critical functions within the industry. The requirements within AS9100 are complementary to contractual and applicable law and regulations. Those implementing a quality system compliant with AS9100 must ensure that the additional requirements of their customers, regulatory agencies and local, state and national laws are also referenced within the system's documentation.

Within AS9100, additions and clarifications have been made to most areas of ISO 9001. Some additional expectations relevant to the aerospace industry will be emphasized in this article. Most are based upon existing best practices, which are collected and formatted in AS9100 to ensure that manufacturers meet the industry's expectations.

The AS9100 standard provides guidance for managing variation when a "key characteristic" is identified. Keys are features of a material, process or part in which the variation has a significant influence on product fit, performance, service life or manufacturability. AS9100 requires that an organization establish and document a configuration management process.

Planning product realization is essential for effective and efficient processes. The standard emphasizes planning for in-process verification when a product can't be verified at a later point. Tooling design must also be considered when process control methodology is used to ensure that process data will be captured.

The AS9100 standard includes extensive supplementation in design-and-development functions due to complexity of aerospace products and customers' expectations for reliable performance 
during a protracted period of time. The European version of AS9100 standard EN9100 provides many of these additions. Both standards cover planning for design-and-development activities and ensuring interim control points during the design process. Design outputs are supplemented to provide identification of key characteristics, and the data essential for the product that will be identified, manufactured, inspected, used and maintained is detailed.

Notes are included for both design-and-development verification and validation highlighting traditional areas of emphasis. Additionally, AS9100 provides information on areas of verification documentation and validating testing and results.

Managing suppliers throughout the aerospace supply chain remains a major challenge for the industry. The chain is very long, and within the supply base, there are sources that serve multiple industries. Because the industry is so dependent upon this supply chain, it isn't surprising that AS9100 includes a number of additional expectations for identifying and maintaining suppliers. Supplier approval is just one step in the process of managing suppliers. Effectively communicating requirements is essential. The standard lists seven specific areas for consideration. They range from clarifying engineering requirements to managing test specimens and right of access to suppliers' facilities. The industry typically relies upon one of three methods for product acceptance. An organization might conduct a receiving inspection, perform the inspection at the supplier's facility or formally delegate product acceptance to the supplier. Procedures for determining the method of supplier control are required, as are the processes used when employing these methods. The most important element of this area of the standard is understanding that a supplier is responsible for managing its own suppliers and subtier suppliers. This includes performing special processes that are frequently subcontracted to processing houses. The supplier must use customer-approved sources; however, ensuring that the processing is properly performed is the supplier's responsibility.

Manufacturing a product as sophisticated as an airplane or space vehicle requires special attention during the production processes. It's important to ensure that the correct revision of the engineering documentation is being used and documented within the quality documents and that work performance is recorded. Controlling production processes is essential to demonstrate that operations have been correctly performed. This is especially important when conducting special processes that don't lend themselves to after-the-fact inspection techniques.

The industry frequently relies upon tooling and other production equipment, including computercontrolled machines, to fabricate and assemble products. This equipment often forms the basis for product acceptance. In these cases, it's essential to demonstrate the integrity of these tools and machines and to develop a process that will ensure adequate oversight of the entire process.

Aircraft are designed to perform for 50 years or more, and properly maintaining the aircraft is essential for continued safe operation. Therefore, servicing requirements are an important part of the total quality management system. These include maintenance and repair manuals as well as the actual servicing work. Again, record keeping is important in documenting the work performed, the equipment used and the people doing the work.

Some products require traceability of part or all of their components. This requirement may be imposed by contract, regulatory agency or internal needs. In any case, AS9100 standard provides the essentials of an effective traceability program.

Using measuring devices of known accuracy including computer-assisted measuring and test equipment is essential in the verification process. Maintaining a calibration history of this equipment and documented proof that it's reviewed and verified periodically underlies the entire metrology system.

Diagnosing the quality management system's health and using this information to guide improvement activity is important for efficiency and effectiveness. Internal audits performed by competent personnel are a vital input into this health measurement system. AS9100 provides some additional expectations regarding internal quality audits.

Detailed first-article inspections are frequently performed to demonstrate product conformance to engineering requirements. Documenting the actual inspection and test results is an established method of demonstrating initial item acceptance. The standard provides general direction in this regard and suggests that additional standard requirements should be consulted for further guidance. Another international aerospace standard, called AS9102 and developed by the IAQG, outlines a methodology for performing and documenting first-article inspections. 
When things don't go as planned, AS9100 gives directions for controlling and disposing nonconforming material. This includes specific requirements for contacting the customer for authorization when using or repairing a product that doesn't conform to engineering requirements.

The current version of AS9100 standard issued in 2009 (Revision C) fully aligns the with ISO 9001:2008 standard and those extra requirements regarding Regulatory Compliance and the aerospace-sector specific requirements have been additionally addressed in the following areas of the standard (SAE AS9100C):

- Scope statement includes "Aviation, Space and Defense";

- Configuration management - The organization shall establish, implement and maintain a configuration management process that includes, as appropriate to the product: configuration management planning, configuration identification, change control, configuration status accounting, and configuration audit;

- Design phase, design verification, validation and testing processes - ensures that design responsible organizations have a robust design process to meet safety and reliability requirements demanded by the aerospace industry;

- Reliability, availability and maintainability - In planning product realization, the organization shall determine the following, as appropriate quality objectives and requirements for the product reliability, availability and maintainability;

- Control of Suppliers - The organization shall maintain a register of its suppliers that includes approval status and the scope of the approval, periodically review supplier performance; the results of these reviews shall be used as a basis for establishing the level of controls to be implemented, define the necessary actions to take when dealing with suppliers that do not meet requirements, ensure where required that both the organization and all suppliers use customerapproved special process sources, define the process, responsibilities and authority for the approval status decision, changes of the approval status and conditions for a controlled use of suppliers depending on the supplier's approval status, and determine and manage the risk when selecting and using suppliers;

- Verification of purchased product - The organization shall establish and implement the inspection or other activities necessary for ensuring that purchased product meets specified purchase requirements;

- Product realization - ensures that each phase of product realization, from planning to shipment, is tightly controlled for delivery of conforming product;

- Identification and traceability - The organization shall maintain the identification of the configuration of the product in order to identify any differences between the actual configuration and the agreed configuration;

- First article inspection - The organization shall use a representative item from the first production run of a new part or assembly to verify that the production processes, production documentation and tooling are capable of producing parts and assemblies that meet requirements. This process shall be repeated when changes occur that invalidate the original results (e.g., engineering changes, manufacturing process changes, tooling changes);

- Risk Management - New requirement of implementation of a risk management process applicable to the projects \& products, responsibility, criteria, mitigation $\&$ acceptance;

- Formal monitoring of customer satisfaction data - Added the requirement to monitor data and to develop improvement plans that address deficiencies with the intent to promote continuous improvement of the product and customer satisfaction;

- Project Management - New requirement for planning and managing product realization in a structured and controlled way.

AS9100 promotes continual improvement as ISO 9001 and puts more emphasize on this process as core process in the standard. The organization is supposed to establish, document, implement, maintain and continually improve quality management system. Diagram at the figure 2 simply explains this process (Myhrberg and Crabtree, 2006):

\section{CONCLUSION}

Implementing AS9100 will motivate staff by defining their key roles and responsibilities. Cost savings can be made through improved efficiency and productivity as product or service deficiencies will be highlighted. From this, improvements can be developed, resulting in less waste, inappropriate or rejected work and fewer complaints. Customers will notice that orders are met consistently, on time and to the correct specification. This can open up the market place to increased opportunities. An 
additional benefit due to the standardised processes and procedures is the reduction in multiple expectations due to the consistency in verification.

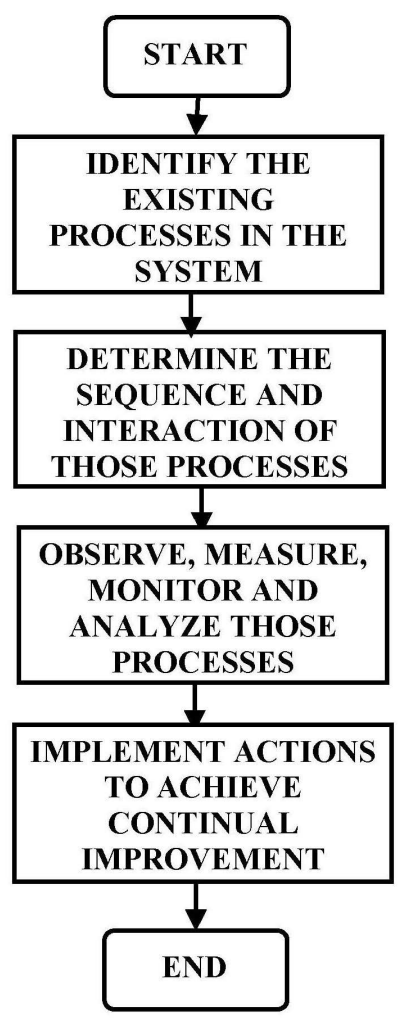

Figure 2: Basis for Aerospace Quality Management System

Implementation of AS9100 should start with identification of AS9100 requirements and how they apply to the business involved, establishing quality objectives and how they fit in to the operation of the business, producing a documented quality policy indicating how these requirements are satisfied, communicating them throughout the organisation, evaluating the quality policy, its stated objectives and then prioritize requirements to ensure they are met, identification of the boundaries of the quality management system and producing documented procedures as required, ensuring that these procedures are suitable and adhered to and once developed, undertaking internal audits to ensure the quality management system carries on working.

The implementation of AS9100 assures customers that the company has a good Quality Management System (QMS). An organization with an effective QMS will typically meet customer expectations better than an organization that does not have an effective QMS. Many aerospace organizations require their suppliers to have AS9100 Registration. AS9100-based Quality Management System has been proven over the years that it leads companies to better operations, improved performance, and improved profitability. Feedback from AS9100 Registered companies shows what it can be expected as the payoff from all of hard work implementing the Quality Management System. AS9100 includes all of the elements of ISO 9001, as well as additional requirements specific to the aerospace industry. Because of the responsibilities called out in the AS9100 standard, organizations often see an increased involvement of top management with regards to the Quality Management System. AS9100 provides the mechanism of reviewing goals and performance against goals on a scheduled basis, and for taking action based on the evaluation. Also, increased productivity results from the initial evaluation and improvement of processes that occurs during the implementation process and from improved training and qualification of employees. Better documentation or control of processes leads to consistency in performance, and less scrap and rework. Customer satisfaction increases are seen as Goals and Objectives take the customer needs into account. Customer needs are better understood as customer feedback is sought, received and analyzed. Goals and objectives are adjusted based on the information and the organization becomes more customer driven. As goals focus on the customer, the organization spends less time focusing on individual goals of departments and more time working together to meet customer needs. All of this leads to financial rewards and significant investments in the Quality Management System showing considerable improvement in fiscal performance.

\section{REFERENCES}

Dale, G.K. (January 2010). AS9100 Aerospace Requirements - Above and Beyond. Quality Progress, 60-63.

Myhrberg, E.V., \& Crabtree, D.H. (2006). A practical field guide for AS9100. Milwaukee, USA: American Society for Qualty Press.

Society of Automotive Engineers - SAE (2009). AS9100 Rev. C. 